\title{
A Railway Transportation Safety Assessment Method Based on Safe State Index
}

\author{
YIJIA YANG ${ }^{1, a}$, XIAONING ZHU ${ }^{2, a}$ \\ ${ }^{1,2}$ School of Traffic and Transportation, Beijing Jiaotong University, Beijing, 100044, China \\ a15120905@bjtu.edu.cn
}

\begin{abstract}
Keywords: Railway Safety, Risk Value, Safety Level
Abstract: In order to make a better railway transportation safety system and reduce the number of railway accidents, we establish a safety status index to assess the railway transportation safety level. We calculate the risk value by classifying the safety information provided by the China Railway in accordance with the risk factors of consequence. The combinations of risk value and the level of index weight are used to grasp the overall situation of safety management at all levels. The final result is represented in the form of a safety level which can be used to guide the decisions making during the safety warning.
\end{abstract}

\section{Introduction}

Safety has been the eternal theme of rail transport, with the development of the railway management system reform and science and technology, under the new situation to strengthen railway safety research is the basic guarantee railway sustained and stable development.

In this paper, a railway transportation safety assessment method based on railway transportation safety condition is proposed to measure and predict the safety of the railway.Identification of risk factors for railway transportation is the foundation of the construction of the railway transportation safety state index. Identification method is scientific, reasonable and practical, which will directly affect the accuracy and practicality of the safety state index.In this paper, the research on the identification method of risk factors will start from the classification method of the risk factors, and then establish the early warning index system of railway transportation, and then identify the risk factors.

\section{The evaluation standard based on hazard levels}

According to the implementation steps and specific content of the dangerous factors, the standard of the risk factors is divided into two levels. The first one is to determine the risk which is mainly based on the relevant regulations of the railway, the technical standards and operation regulations. To judge the other one which is to determine the degree of danger based on types of safety information, the appropriate values are given according to the severity of the consequences, which achieves a unified and standardized risk level evaluation.

\section{Discussion on the safety state index of railway transportation}

Safety state index is a comprehensive index of railway safety level. In the framework of the early warning index system, using scientific methods to calculate the safety of all levels' department. The evaluation of the degree of danger is based on all kinds of safety information. According to the index weight of the safety of the consequences caused by the safety information, the unification and standardization of the risk level are realized.

\section{Safety assessment method}

The calculation of safety state index. Safety status index can be used to characterize the safety risk value. According to the safety risk value calculated by each level index, the safety status of all levels 
of indicators was evaluated. Safety early warning level is determined by the level of risk. Once the key sectors of significant safety risks, even if the calculated safety risk value did not reach the warning level, we also need to take safety control measures in time and prevent the occurrence of major accidents.

Railway transportation safety information data sources include accident information, fault information, equipment monitoring information and safety inspection information and red-yellow card information. After decades of development, China has formed a huge safety information database. From the content and the form of feedback in the form of the information, it is classified according to the different levels of safety. According to the basic principle of Hayne's law and the practice of railway safety management, the classification of the consequences of the risk factors is determined. As is shown in Table 1.

Table 1 Classification of the Risk Factors

\begin{tabular}{|c|c|c|c|c|}
\hline Code & $\begin{array}{c}\text { Consequence of } \\
\text { risk factors }\end{array}$ & Definition & Weight & ratio \\
\hline A & $\begin{array}{c}\text { Major liability } \\
\text { accident }\end{array}$ & $\begin{array}{c}\text { the passenger train accident above class B, } \\
\text { the goods train accident above class A, the } \\
\text { employee dies accident above class B }\end{array}$ & 1 & 1 \\
\hline B & $\begin{array}{c}\text { Minor liability } \\
\text { accident }\end{array}$ & $\begin{array}{c}\text { the passenger train accident above class D, } \\
\text { the goods train accident above class C }\end{array}$ & 0.1 & 10 \\
\hline C & Liability fault & $\begin{array}{c}\text { Equipment failure, delay passenger trains or } \\
\text { cause minor injuries, cargo trains accident of } \\
\text { class D }\end{array}$ & 0.02 & 50 \\
\hline D & $\begin{array}{c}\text { Minor liability } \\
\text { failure }\end{array}$ & $\begin{array}{c}\text { Equipment failure, delayed trains, outside } \\
\text { road accidents (B1) }\end{array}$ & 0.01 & 100 \\
\hline E & $\begin{array}{c}\text { Red-yellow } \\
\text { card }\end{array}$ & The railway safety standards issued notice & 0.005 & 200 \\
\hline F & hidden danger & Related to determine the standard & 0.001 & 1000 \\
\hline
\end{tabular}

Risk factors are not only related to the severity of the consequences, but also with the probability of the occurrence of risk factors. Based on this, the risk factors of risk factors are proposed.

$$
R_{i}=A_{i}+B_{i} \times 0.1+C_{i} \times 0.02+D_{i} \times 0.01+E_{i} \times 0.005+F_{i} \times 0.001
$$

Among them:

$R_{i}$ is the risk value for risk factors $\mathrm{i}$;

$A_{i}$ is the number of major accidents in the period of the statistical period for the risk factors;

$B_{i}$ is the number of minor incidents that occurred during the period of the statistics for the risk factors;

$C_{i}$ is the number of chargeable failure in the period of the statistical period for the risk factors;

$D_{i}$ is the number of minor responsibility fault that occurred during the period of the statistics for the risk factors;

$E_{i}$ is the number of noticed received the period of the statistical period for the risk factors;

$F_{i}$ is the number of minor incidents that occurred during the period of the statistics for the risk factors;

According to the early warning index system and the standard of risk factors, safety index value is calculated through the various levels whose structures are five levels to determine the situation of the safety management at different levels.

This shows that the safety assessment mainly includes two parts, one part is the calculation of the safety risk, and the part is the determination of the weight coefficient of each level. In accordance 
with the process of safety information flow, as long as the risk value of the underlying risk factors, and then determine the weight of each level index, from the bottom up, by layer, you can get the safety status of various levels of management departments, and ultimately determine the safety state of the railway corporation. The risk factors of the risk value of the upper section can be drawn, the total risk value of the company's calculation formula for:

$$
F=\sum_{l=1}^{N_{J}} \lambda_{l}\left(\sum_{j=1}^{N_{D}} \gamma_{j}^{l}\left(\sum_{k=1}^{N_{Y}} \mu_{k}^{l j}\left(\sum_{i=1}^{N_{Z}} \xi_{i}^{l j k} \cdot R_{i}^{l j k}\right)\right)\right)
$$

Among them:

$\lambda_{l}$ is the weight of Railway Bureau $\mathrm{L}$ in China Railway Safety Management, which is equivalent or decided by railway length.

$\gamma_{j}^{l}$ is the weight of Segment $\mathrm{J}$ in Railway Bureau L Safety Management, which is determined based on the nature and content of the job.

$\mu_{k}^{l j}$ is the weight of people, equipment, environment and management in the station or Segment, which is determined based on actual field operations.

$\xi_{i}^{l j k}$ is the weight of risk factor $\mathrm{i}$ among all risk factors, which is determined based on an integrated risk factor for the type, nature.

$R_{i}^{l j k}$ is the risk value belonging to factor K from Railway Bureau L Segment J during the period of the statistics for the risk factor $i$.

The weight of each hierarchy is determined. From the above, it can be known that the weight coefficient of index is the key to safety assessment. Weight coefficient is the quantitative characterization of the relative importance of the indicators in the overall evaluation, and the weight of the railway safety early warning indicators may be related to the severity of the consequences. At present, the weight coefficient determination method has the subjective weighting method, the analytic hierarchy process, the maximum entropy technique method and the principal component analysis method. From the point of view of railway safety early warning index system, it has many characteristics, such as many elements, wide influence range, and the uncertainty of the results. Therefore, in the process of determining the weight coefficient of each index, it should be fully integrated with the characteristics of safety information, as far as possible to reflect the impact of various indicators on the safety situation of the railway departments at all levels.

From the calculation process of risk factors, safety information and risk factors are corresponding, and the degree of safety information is classified, and the frequency of safety information is considered, which can be seen as a result, the risk value of risk factors has been considered.

Safety level determination. Safety level is not only the output form of the results of safety assessment, but also the basis for the evaluation of the safety and early warning system. According to the risk factors, the degree of danger, the degree of emergency and the actual situation of railway transportation production, railway transportation safety state is divided into 4 levels, that is, grade 1 (hazard state), grade II (dangerous state), grade III (critical state) and grade IV (safety state). The concrete level is shown in table 2: 
Table 2 Classification of the Risk Factors

\begin{tabular}{|c|c|l|c|}
\hline Safety level & Safe state & \multicolumn{1}{|c|}{ safety situation description } & Alarm display \\
\hline Grade I & $\begin{array}{c}\text { Disaster } \\
\text { status }\end{array}$ & $\begin{array}{l}\text { There are heavy casualties and traffic } \\
\text { accidents, to take special measures to } \\
\text { comprehensively control }\end{array}$ & Red \\
\hline Grade II & $\begin{array}{c}\text { Dangerous } \\
\text { state }\end{array}$ & $\begin{array}{l}\text { Responsible for casualties and traffic } \\
\text { accidents, to take immediate measures to } \\
\text { reform }\end{array}$ & Orange \\
\hline Grade III & $\begin{array}{c}\text { Critical } \\
\text { state }\end{array}$ & $\begin{array}{l}\text { safety failure, more risk, to strengthen } \\
\text { inspection, rectification, attention to } \\
\text { prevention }\end{array}$ \\
\hline Grade IV & Safe state & $\begin{array}{l}\text { Good safety condition, no large body injury } \\
\text { and traffic accident }\end{array}$ & Blue \\
\hline
\end{tabular}

Under the safety level classification, the critical value of the risk is the key to the safety assessment. If the Risk threshold is set high, it will make the higher risk of safety assessment and early warning not timely. If the risk threshold is set low, it will make the overall safety assessment lower and cannot truly reflect the various levels of safety, resulting in human, material and financial resources waste. Therefore, the determination of the critical value of the safety level of risk needs to combine the overall situation of the railway safety, scientific and reasonable determination.

\section{Conclusion}

The risk factors based on the level of safety at the railway transportation safety system, the establishment of safety at all levels of index calculation methods safety administration, and the safety level in accordance with the four safety levels of the danger colors which consisted of red, orange, yellow and blue.

Construction of the railway transportation safety warning management system is a systematic project, involving multi-sector, a wide range of difficulties to implement, and therefore, in the process of system construction in conjunction with the specific situation in a planned, step by step, following the first trial, the basic principles of gradual and orderly progress, to ensure continued system construction, effective manner. In addition, to take full advantage of data existing information management systems, good interface conversion between the professional data systems, promote the process of informatization of railway transportation safety management, improve early warning support capabilities railway safety management.

\section{Acknowledgment}

This paper was supported by the subject China Railway named Research on the key technology of railway transportation safety early warning system (2014F028).

\section{References}

[1] Miltos Kyriakidis. Data based framework to identify the most significant performance shaping factors in railway operations. Safety Science. Volume 78, October 2015, Pages 60-76

[2] Grigore M. Havârneanu. A systematic review of the literature on safety measures to prevent railway suicides and trespassing accidents. Accident Analysis \& Prevention. Volume 81, August 2015, Pages 30-50

[3] Anne Silla and Veli-Pekka Kallberg. The development of railway safety in Finland. Accident Analysis \& Prevention. Volume 45, March 2012, Pages 737-744 